\title{
NOTAS SOBRE LA EFICACIA SOCIAL DE DISTINTOS TIPOS DE NORMAS CIVILES * **
}

\author{
Jesús Delgado Echeverría \\ Universidad de Zaragoza
}

RESUMEN. El criterio de eficacia social de las normas como cumplimiento o, en otro caso, aplicación, que habitualmente se ofrece desde la teoría general del Derecho, es muy limitado y deja fuera del análisis a todas las normas distintas de las de mandato (obligación o prohibición). Con ello resulta inaplicable a la mayor parte de las normas de Derecho privado, pues en éste son minoría las normas de mandato "imperativas". Predominan, con mucho, las permisivas y las que atribuyen poderes y determinan las condiciones de su ejercicio y las "dispositivas", relacionadas con las anteriores. Son necesarios otros criterios (distintos del de cumplimiento/aplicación) para apreciar la eficacia social de estos tipos de normas civiles. En este trabajo se exploran criterios de eficacia y efectividad social de los diversos tipos de normas de Derecho privado, trayendo a contribución puntos de vista de la teoría general del Derecho, de la sociología jurídica y de la "ciencia de la legislación".

Palabras clave: eficacia, normas imperativas, normas permisivas, normas que confieren poderes, normas dispositivas.

ABSTRACT. To consider obedience or application of rules as a criterion for their social effectiveness as it is usually done by General Legal Theory is a too narrow criterion. In fact, it does not include into the analysis but mandatory norms (i.e. obligation or prohibition norms). In this respect, the criterion is unable to explain most of private Law norms, where most of the norms are not of the mentioned kind, but rather permissive and power-conferring rules, dispositive rules and those related to them. Other criteria are required (different to obedience and application) so to determine the social effectiveness of these civil norms. In this article different criteria of social effectiveness and social efficiency of the different sorts of private Law norms are explored. For that purpose contributions from different perspectives such as General Legal Theory, Legal Sociology and Legislative Science are brought into consideration.

Keywords: effectiveness, imperative norms, permisive norms, power-conferring rules, dispositive norms.

* Trabajo realizado en el marco del Proyecto de Investigación SEJ2005-05790, «Validez de los actos jurídicos de Derecho privado», financiado al $50 \%$ por el Ministerio de Ciencia y Tecnología y los fondos FEDER y del que soy investigador principal.

$* *$ El texto de este artículo fue discutido en febrero de 2007 sucesivamente en el Seminario del Grupo de Investigación "Nulidad", de la Universidad de Zaragoza, que yo dirijo, y en el Seminario de Filosofía del Derecho de la Universidad de Alicante, que dirige Manuel AtIENZA. Muchas gracias a todos los que intervinieron en estas sesiones, especialmente a los hospitalarios colegas de Alicante, por la crítica a que sometieron mis ideas. 


\section{DEFINICIONES DE EFICACIA Y DE EFECTIVIDAD DE LAS NORMAS}

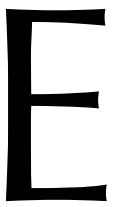

s usual en la teoría del Derecho la definición de la eficacia social de las normas por referencia al cumplimiento de las mismas o, caso de incumplimiento, su aplicación por el juez ${ }^{1}$. Cumplimiento y aplicación resultan así las claves para la definición de eficacia.

Es también habitual la distinción entre este concepto de eficacia y el de eficacia o efectividad social como «capacidad para obtener, por medio de normas jurídicas, estados de cosas socialmente valiosos» ${ }^{2}$.

La consecución de determinados estados de cosas es el fin que el legislador se ha propuesto $^{3}$. Al diseñar la ley, sólo después de determinados los fines procede considerar qué normas serían aquellas que, caso de ser cumplidas, producirían el estado de cosas socialmente valioso deseado (acorde con los fines), y qué otros efectos, deseables o no, es previsible que de tales normas deriven; después —en realidad, simultáneamente, o en procesos iterativos-, si tales normas pueden ser cumplidas y si es previsible que lo sean, qué obstáculos encontrarán para ello, qué otras medidas legales o de otro tipo son necesarias o útiles para lograr el cumplimiento, cómo incentivar el cumplimiento; se plantean también cuestiones sobre la aplicabilidad de las normas en caso de incumplimiento, necesidad de normas procesales u orgánicas de los tribunales, ejecutabilidad de las sentencias.

En la teoría del derecho, el análisis del concepto de eficacia parte del concepto de cumplimiento. Se entiende que a través del cumplimiento de la norma se consiguen los resultados y consecuencias considerados valiosos para la sociedad; o bien, en caso de incumplimiento, la aplicación de la norma por los jueces trata de conseguir resultados equivalentes ${ }^{4}$.

${ }^{1}$ Esta noción se remonta al menos a KELSEN (KELSEN, H., 1960: Reine Rechtslebre, 2. a y definitiva edición, revisada y ampliada, Viena; trad. del original en alemán por VERNENGO, R. J., 1979: Teoría pura del Derecho, México: Universidad Nacional Autónoma de México, p. 24).

2 Navarro, P. E., 1990: La eficacia del derecho. Una investigación sobre la existencia y el funcionamiento de los sistemas jurídicos, Madrid: Centro de Estudios Constitucionales, p. 19. La terminología no está totalmente fijada: por ejemplo, DíEz RIPOLLÉs utiliza de manera inversa efectividad y eficacia, siguiendo quizás pautas de la penalística alemana: cumplimiento y aplicación «se ocupan de la efectividad de la norma, esto es, de su puesta en práctica o vigencia», mientras que la eficacia se refiere a la obtención (mediante el cumplimiento o la aplicación) de los objetivos de tutela perseguidos (DíEz RIPOLLÉs, J. L., La racionalidad de las leyes penales. Práctica y teoría, Madrid: Trotta, p. 95).

3 Desde el punto de vista de la política legislativa, AtIENZA considera la efectividad social de las normas («¿alcanza la ley los fines sociales perseguidos?») como el valor de referencia en el nivel de la racionalidad teleológica (R4); mientras que el valor de referencia en el nivel de la racionalidad pragmática (R3) es la eficacia: «que las normas sean obedecidas o, dicho quizás en forma más general, que las leyes no sean sólo enunciados lingüísticos, sino “Derecho en acción” (ATIENZA, M., 1997: Contribución a una teoría de la legislación, Madrid: Cuadernos Civitas).

${ }^{4}$ La equivalencia de los resultados es, sin embargo, muy relativa. No es lo mismo una situación en que los ciudadanos se abstienen de cometer delito que otra en que las cárceles están superpobladas porque los jueces, aplicando correctamente las leyes, condenan a los que cometen delitos. La valoración social de estos resultados es muchas veces ambigua: ¿es un éxito que aumente el número de condenas por violencia doméstica, tráfico de estupefacientes, delitos ecológicos...? Cfr. Ost, F., y vAN DE KERCHOVE, M., 2002: De la pyramide au réseau? Pour une théorie dialectique du droit, Bruxelles: Publications des Facultés universitaires SaintLouis, p. 330. 


\section{EFICACIA COMO CUMPLIMIENTO}

Ahora bien, el concepto de cumplimiento de normas es todo menos claro o sencillo. Aquí, y por su estrecha relación con el Derecho civil, me interesan estos dos aspectos:

a) Cumplimiento parece que sólo puede predicarse respecto de normas regulativas de mandato ${ }^{5}$, es decir, de las que ordenan o prohíben (con los operadores deónticos de obligación o prohibición). No cabría cumplimiento de normas permisivas; tampoco respecto de las que atribuyen poderes (normas de competencia); menos aún respecto de normas puramente constitutivas o de enunciados conceptuales, como las definiciones. Tampoco parece que "cumplimiento" sea un concepto adecuado para entender la eficacia de las normas dispositivas o supletorias, que constituyen, junto con las otras categorías distintas de las regulativas de mandato, la inmensa mayor parte de las normas contenidas en los códigos civiles. En consecuencia, el análisis de la eficacia de las normas debe ser completado y enriquecido ampliamente para que sea verdaderamente útil en el campo del Derecho civil ${ }^{6}$. En realidad, mantener el concepto de eficacia estrictamente relacionado con el de cumplimiento parece reflejar la concepción elemental de los sistemas jurídicos como conjunto de mandatos respaldados por amenazas y resulta adecuado únicamente, si acaso, para el análisis de las normas penales (los delitos como incumplimiento).

b) Cumplimiento no es la mera correspondencia de la acción de los sujetos con el contenido prescriptivo de la norma, sino que requiere no sólo el conocimiento de la misma, sino que ésta haya servido de motivación para la acción.

Las cuestiones suscitadas en $a$ ) y b) están interrelacionadas, y así se plantean explícitamente en la literatura especializada. P. NAVARRO ${ }^{7}$ distingue entre "correspondencia", "acatamiento" y "cumplimiento" del siguiente modo: «Una norma $(\mathrm{N})$ prescribe el estado de cosas o la acción $p$ y los sujetos normativos producen $p$ (correspondencia); «Una norma $(\mathrm{N})$ prescribe el estado de cosas o la acción $p$, los sujetos normativos conocen la existencia de $(\mathrm{N})$ y producen $p$ (acatamiento); «Una norma $(\mathrm{N})$ prescribe el estado de cosas o la acción $p$, los sujetos normativos conocen la existencia de (N) y producen $p$ en virtud de ( $N$ )» (cumplimiento).

Pues bien, en su opinión, «explicar el concepto de eficacia solamente en términos de correspondencia no pone de manifiesto que el predicado "eficacia" es utilizado

5 Sigo la terminología de ATIENZA y RUIZ MANERO en la clasificación de los enunciados jurídicos (ATIENZA, M., y Ruiz Manero, J., 2004: Las piezas del Derecho. Teoría de los enunciados jurídicos, 2. ${ }^{a}$ ed. actualizada, Barcelona: Ariel, vid. en particular cuadros de pp. 201 y ss.).

${ }^{6}$ Algunas limitaciones de la noción que identifica eficacia con incumplimiento y aplicación son puestas de manifiesto por DI LUCIA, «Agire secondo una norma, agire per una norma, agire in funzione di una norma», en Comanducci, P., e Guastini, R. (coords.), 1996: Struttura e dinamica dei sistemi giuridici, Torino: Giappichelli ed., pp. 37-45.

Autores más alejados de la filosofía analítica, al advertir la existencia de tipos de normas respecto de las cuales no cabe hablar propiamente de cumplimiento, proponen superar el concepto de eficacia como capacidad de la regla para orientar el comportamiento de sus destinatarios en el sentido deseado por el legislador y sustituirlo por uno más amplio según el cual la regla es eficaz si es utilizada por sus destinatarios como modelo para orientar su actividad práctica (OST y KeRCHOve, 2002: pp. 229-230, con cita de P. AmSELEK y otros autores).

7 NAVARRO, 1990: p. 16. 
naturalmente en el caso de aquellos enunciados destinados a promover conductas, es decir, prescripciones». «El concepto de eficacia tiene que explicarse de manera tal de vincularlo específicamente con el concepto y función de las prescripciones», precisamente porque «la función de las prescripciones es promover o evitar ciertas conductas. Por consiguiente, es un error desvincular el concepto de eficacia de los sistemas normativos de la función motivadora que caracteriza a estos sistemas». En definitiva, «un concepto de eficacia útil para la teoría jurídica es dependiente del concepto de prescripción. La simple relación de correspondencia no puede constituir, sin distorsión del concepto de prescripción, el concepto de asignación de eficacia (aun cuando pudiese ser de ineficacia)» ${ }^{8}$.

Ésta es una importante limitación de la concepción de la eficacia como cumplimiento, pues sólo tiene sentido respecto de las normas regulativas de mandato (que obligan a hacer algo o prohíben hacer algo). Quedan fuera las normas regulativas de permisión, así como las que confieren poderes, las constitutivas y los enunciados legales puramente conceptuales, como las definiciones. NAVARRO lo afirma expresamente para las primeras mencionadas:

«Incidentalmente, esto arroja luz sobre un punto importante: no tiene sentido predicar eficacia en el caso de las normas permisivas. La característica distintiva de la eficacia no es la existencia de una correspondencia sino el carácter deóntico de la norma en cuestión. Esto se demuestra claramente al considerar dos normas, una que permite el contenido proposicional $p$ y otra que obliga a producir $p$. Supongamos que los sujetos normativos hacen - $p$. Sólo en el segundo caso es natural predicar ineficacia, aun cuando sea verdadero también del primer caso que no existe relación de correspondencia entre las acciones de los sujetos y los contenidos normativos. Esto no significa que las normas permisivas sean irrelevantes, ya que éstas son una importante herramienta de análisis de la dinámica de los sistemas jurídicos»? .

Comenzaré con una observación sobre la última frase, según la cual las normas permisivas son «una importante herramienta de análisis»y, al parecer, ninguna otra cosa. Como si las normas permisivas - en el sentido amplio en que parece utilizado el término: las regulativas que no son de mandato- carecieran de toda función sustantiva, de toda relevancia social distinta de la de ser «herramientas de análisis».

\section{3. “CUMPLIMIENTO” DE NORMAS DISTINTAS DE LAS DE MANDATO}

El caso es que parte importante de las normas de Derecho civil son de permiso, aunque frecuentemente actúan acompañadas de otras de mandato dirigidas a los terceros o a la autoridad (así pueden analizarle las normas que atribuyen derechos subjetivos).

Cabe intentar una apreciación de la eficacia de las normas permisivas desde este punto de vista, sin renunciar a la implicación entre eficacia y cumplimiento. Si la permisión va acompañada del deber de otros sujetos de no impedir la acción permitida,

\footnotetext{
8 NaVARro, 1990: pp. 55-57.

9 NAVARro, 1990: p. 56.
} 
y en la mayor parte de los casos los terceros no infringen este deber de abstención (o, cuando lo infringen, los tribunales remueven el obstáculo y sancionan al infractor), la norma de permiso sería eficaz.

Las normas que atribuyen poderes (contraer matrimonio, contratar, testar...) van acompañadas en el Derecho privado, de ordinario, por normas de permiso (el ejercicio de los poderes de Derecho privado es, de ordinario, discrecional). Cabría apreciar su eficacia atendiendo al cumplimiento de los correlativos deberes de los terceros (prohibición de interferir).

Para las normas constitutivas —o algunas de ellas_- podríamos decir de forma análoga que son eficaces si los demás no discuten el estado o situación constituido por la norma o si, en el caso de que lo discutan o impidan sus consecuencias, los tribunales declaran la situación producida e imponen sus consecuencias. Por ejemplo, la norma que atribuye la mayoría de edad por el cumplimiento de los dieciocho años podría analizarse de este modo desde el punto de vista de la eficacia: es eficaz si en la mayor parte de los casos los mayores de dieciocho años son tratados como mayores de edad.

Generalizando, podríamos decir que una norma de permiso, una norma de competencia o una norma constitutiva es ineficaz si los demás sujetos impiden la acción permitida o las consecuencias de la situación adquirida y los tribunales no sancionan esta conducta.

Un concepto de eficacia - y de ineficacia - como el anterior, que sigue basado en el criterio del cumplimiento (o, si no, aplicación) tiene alguna utilidad. Ciertamente, no es indiferente desde el punto de vista de la consecución del estado de cosas deseado por el legislador que se impida actuar a los sujetos en los supuestos en que el legislador permite la acción sin que los tribunales garanticen la posibilidad de la acción permitida. Pero ¿podemos decir que todas las normas que, según este criterio, no son ineficaces, están dotadas de eficacia social?

\section{4. ¿ES SOCIALMENTE IRRELEVANTE LA “MERA COINCIDENCIA”?}

Como hemos visto, para NAVARRO la mera correspondencia entre la conducta de los destinatarios de la norma y el contenido de ésta (coincidencia), prescindiendo de los motivos de la conducta y aun del conocimiento que los sujetos puedan tener de la norma, es irrelevante para apreciar la eficacia de las normas. También Liborio HIERRO sostiene que «una investigación de la eficacia-correspondencia arrojaría resultados sin ninguna capacidad explicativa sobre la función de la(s) norma(s) investigada(s) y sin ninguna utilidad político-jurídica» ${ }^{10}$.

HiERRO propone como ejemplo histórico la promulgación del Fuero Juzgo por Fernando III, quien, según dice, «lo que en realidad estaba haciendo era legislar Derecho consuetudinario, lo que, con toda probabilidad, le dotaba de un alto grado de correspondencia en cuanto que la conducta de todos los que, por costumbre, estu-

${ }^{10}$ Hierro, L., 2003: La eficacia de las normas jurídicas, Barcelona, Ariel, p. 77. Asimismo LAPORTA, F. J., «Poder y Derecho», El derecho y la justicia, Enciclopedia Iberoamericana de Filosofía, Madrid, Trotta, 2. ${ }^{\mathrm{a}}$ ed., p. 451. 
vieran cumpliendo las prescripciones del Liber se convertía automáticamente, aun sin ellos saberlo, en una conducta correspondiente al Fuero Juzgo». Para lo que sigue, doy por buenas estas apreciaciones.

El ejemplo no puede menos de llamar la atención de un civilista. En realidad, la mayor parte del Derecho civil codificado recoge Derecho anterior, ya seguido y practicado por los destinatarios de la norma antes de que fuera promulgada - o nuevamente promulgada - como ley. Así ocurre, señaladamente, con el Código civil español, según preveía la Ley de Bases ${ }^{11}$.

Promulgar como ley lo que ya es observado y practicado en la sociedad es conducta muchas veces repetida por los legisladores, que afianzan de este modo la legitimación de su poder. Fue fenómeno corriente en la Edad Media (los reyes querían aumentar su poder como legisladores, frente a la resistencia de unos súbditos que oponían la validez de sus usos y costumbres, inmunes al poder real), pero también hoy podemos observarlo en su manifestación más pura cuando legisladores estatales aprueban sistemas de Derecho indígena o, más cerca de nosotros, al producirse la transmutación en ley autonómica del Derecho consuetudinario guipuzcoano ${ }^{12} \mathrm{o}$ de las reglas consuetudinarias de los arrendamientos rústicos valencianos ${ }^{13}$.

Tales operaciones legislativas tienen indudable eficacia en la configuración de las relaciones sociales. Además de contribuir a legitimar el poder, tales actos de legislación cumplen sin duda otras funciones. Siguiendo los esquemas propuestos por Vincenzo FERRARI ${ }^{14}$, la nueva legislación, aun coincidente con lo ya de antemano observado, facilita el tratamiento de los conflictos declarados, al menos por cuanto ahora las normas aplicables no requieren averiguación y prueba, pues ya están recogidas en una ley que los jueces tienen la obligación de conocer y aplicar. Más aún, quizás hasta el momento de la promulgación de la ley los Tribunales no estaban obligados a aplicar las normas consuetudinarias, o tenían prohibido hacerlo; y, en adelante, quizás aplicarán tan sólo, o preferentemente, las normas legisladas, y no posibles normas consuetudinarias anteriores no recogidas en la ley o formadas con posterioridad. De este modo la ley orienta la conducta de los jueces, pues supone verdadera innovación en el "sistema del juez". Todo lo cual contribuirá también a orientar las conductas de los súbditos, que pueden conocer con mayor facilidad las normas aplicables, prever su

${ }^{11}$ Ley de Bases de 11 de mayo de 1888 por la que se autoriza al Gobierno para publicar un Código civil con arreglo a las condiciones y bases establecidas en la misma. Base $1{ }^{a}{ }^{a}:$ «El Código tomará por base el proyecto de 1851, en cuanto se halla contenido en éste el sentido y capital pensamiento de las instituciones civiles del derecho histórico patrio, debiendo formularse por tanto este primer cuerpo legal de nuestra codificación civil sin otro alcance y propósito que el de regularizar, aclarar y armonizar los preceptos de nuestras leyes, recoger las enseñanzas de la doctrina en la solución de las dudas suscitadas por la práctica, y atender a algunas necesidades nuevas con soluciones que tengan un fundamento científico, o un precedente autorizado en legislaciones propias o extrañas, y obtenido ya común asentimiento entre nuestros jurisconsultos, o que resulten bastante justificadas, en vista de las exposiciones de principios o de método hechas en la discusión de ambos Cuerpos Colegisladores». Los términos en cursiva corresponden literalmente a los utilizados casi un siglo después por la Constitución de 1978 para indicar el alcance posible de los textos refundidos (art. 82.5).

${ }_{12}$ Ley (País Vasco) 3/1999, de 26 de noviembre, «de modificación de la Ley del Derecho civil del País Vasco, en lo relativo al Fuero Civil de Guipúzcoa».

${ }^{13}$ Ley (Comunidad Valenciana) de 15 de diciembre de 1986, sobre arrendamientos históricos valencianos.

${ }^{14}$ FerRari, V., 2000: Acción jurídica y sistema normativo. Introducción a la sociología del Derecho, trad. cast., Madrid: Dykinson, p. 271; 1989: Funciones del Derecho, trad. cast., Madrid, Debate, caps. IV y ss. 
aplicación por los jueces y saber que el aparato coactivo del poder político impondrá la ejecución de sus sentencias.

Todos estos fenómenos, de importancia nada desdeñable, son efectos de la ley ("eficacia social de las normas"), aun en la hipótesis de que el contenido de las normas coincida exactamente con la conducta ya observada por sus destinatarios y aun en el caso de que esta conducta tampoco cambie en el futuro.

\section{5. “INVOCAR LA LEY": ENTRE EL CUMPLIMIENTO Y LA APLICACIÓN}

«Cumplimiento e invocación del Derecho» se titula uno de los capítulos de la Introducción a la Sociología del Derecho de Roger COTTERRELL ${ }^{15}$. "Invocar el Derecho" es tomar la iniciativa el ciudadano para hacer uso de los remedios jurídicos que el Ordenamiento pone a su disposición. Entre el cumplimiento (voluntario) y la aplicación de la norma civil por los jueces se interpone la iniciativa del particular que invoca y pide que se aplique para dar satisfacción a sus intereses.

La invocación del Derecho tiene un papel importante en todas las ramas del mismo (las denuncias de los particulares pueden ser decisivas para la aplicación de las normas penales o administrativas), pero es en el Derecho privado donde tienen un lugar central. En palabras del mismo CotTerReL, «en el terreno del Derecho civil (...) contractual y de responsabilidad civil por faltas, el Estado solamente pone los medios de ejecución, dejando al ciudadano la iniciativa de la acción para hacer uso de esos medios» ${ }^{16}$.

En efecto, en el Derecho privado no hay agentes públicos que velen para impedir los incumplimientos de las normas o procedan a sancionar de oficio cuando éstos se producen. Es el particular interesado quien, si quiere, invocará el Derecho (ejercitará su derecho) exigiendo cumplimiento a otro particular y, si es desatendida por éste su reclamación, poniendo en marcha un proceso en que se apliquen las normas hasta la ejecución coactiva si es necesaria, y siempre a impulso del particular.

En el Derecho privado, todas las normas son disponibles ${ }^{17}$, en el sentido de que los favorecidos por ellas pueden, ciertamente, invocarlas; pero pueden también, facultativamente, con plena libertad, no invocarlas, con lo que no habrá ocasión de que los Tribunales (ni autoridad alguna) las apliquen. No es sólo que los particulares puedan, de ordinario, renunciar a sus derechos, sino que incluso en los supuestos en que la renuncia no les está permitida (por ser contraria al interés o el orden público, o en perjuicio de tercero: art. 6.2 CC) pueden lícitamente no hacer nada, no invocar la norma, con lo que ninguna autoridad del Estado podrá aplicarla.

Debe distinguirse, por tanto, desde el punto de vista de la eficacia de las normas civiles, los casos en que, invocada la norma incumplida, los Tribunales no la han apli-

${ }^{15}$ CotTerRell, R., 1991: Introducción a la Sociología del Derecho, trad. cast., Barcelona: Ariel, pp. 209 y ss.

${ }^{16}$ CotTerRell, 1991: p. 211.

${ }_{17}$ Russo, E., 2000: L'interpretaziones delle leggi civili, Torino: Giappichelli ed., pp. 174 y ss.; 2001: «Norma imperativa, norma cogente, norma inderogabile, norma indisponibile, norma dispositiva, norma suppletiva», Rivista di Diritto civile, XLVII, sept.-oct., pp. 573 y ss. 
cado y aquellos otros (que pueden ser mucho más numerosos) en que el particular no tomó ninguna iniciativa. Puede decirse que no hay incumplimiento, en el Derecho privado, mientras el particular no exija el cumplimiento; aun entonces, no hay posibilidad de aplicación de la norma por los Tribunales mientras no se invoque el Derecho ante ellos.

Por tanto, pueden darse las tres situaciones siguientes:

a) La norma es "incumplida" (no se paga lo debido según contrato, no se indemniza el daño causado...) sin que el perjudicado exija cumplimiento.

b) Exigido extrajudicialmente el cumplimiento, éste no se produce y el interesado no acude a los Tribunales.

c) Exigido el cumplimiento ante los Tribunales, éste no se consigue.

Los casos $a$ ) y b) no pueden considerarse sin más casos de incumplimiento. Un número alto de ellos puede considerarse normal en todo sistema jurídico. Un número muy bajo de casos del tipo b), es decir, una situación en que toda falta de cumplimiento espontáneo lleve a "invocar el Derecho" ante los Tribunales parece poco deseable. Los particulares pueden encontrar menos costoso (en tiempo, preocupación y dinero) evitar la oficialización del conflicto, quizás mediante arreglos y transacciones, pero quizás también mediante el simple no hacer nada. En el Derecho privado, el cumplimiento y la aplicación de las normas no son valores absolutos. Prima la libertad de los sujetos, que invocan el Derecho sólo si quieren.

\section{NORMAS DE PERMISO Y DE COMPETENCIA. EFICACIA COMO ÉXITO}

Se habrá observado que, de acuerdo con el concepto de eficacia como cumplimiento, aplicado a las normas de permiso (supra, 3), éstas serían eficaces aunque ningún sujeto realizara nunca la acción permitida (y las normas constitutivas podrían ser eficaces aunque no se diera nunca el hecho previsto). Para NAVARRO, en el párrafo transcrito, si una norma permite el contenido proposicional $p$ y los sujetos no hacen $p$, no es «natural predicar ineficacia», «aun cuando sea verdadero también (...) que no existe relación de correspondencia entre las acciones de los sujetos y los contenidos normativos». Ciertamente, para este autor, como hemos visto, «no tiene sentido predicar eficacia en el caso de las normas permisivas».

Pero más adelante NAVARRO hace la siguiente observación: la institución de la enfiteusis en el Derecho argentino sería uno de los casos «a los que los juristas podrían calificar de ineficaces y simultáneamente afirmar su existencia» ${ }^{18}$. La enfiteusis, en efecto, parece ser una de las instituciones que primero viene a las mientes de un jurista como ejemplo de institución ineficaz (por cierto, NAVARRO no da ninguna explicación de qué deba entenderse por institución ineficaz: podemos entender que cuando son ineficaces las normas, en principio permisivas, que la regulan). Pero es el caso de que, aunque nadie, durante mucho tiempo, constituyera una enfiteusis (e incluso se hubieran extinguido todos los derechos reales de enfiteusis que por tiempo fueron), las

${ }^{18}$ NaVARro, 1990: p. 75. 
normas reguladoras de la enfiteusis no serían ineficaces con arreglo al anterior criterio: nadie las ha incumplido ni han dejado de ser aplicadas por los jueces cuando el caso se ha presentado. Sin embargo, parece muy razonable cuestionar la eficacia de normas tales, como de hecho se hace a menudo sin mayores explicaciones. Parece que respecto de las normas distintas de las de mandato la realización de conductas correspondientes con ellas —o la producción de los supuestos de las normas constitutivases un elemento necesario del concepto de eficacia, aunque tales conductas no sean, por hipótesis, cumplimiento (si bien fácilmente puedan significar acatamiento, es decir, incluyen el conocimiento de la norma).

Para este segundo concepto de eficacia de las normas distintas de las de mandato parece que hay que partir de la eficacia social pretendida por el legislador: de la finalidad con que ha dictado la norma y la previsión que ha hecho sobre su utilización por los sujetos jurídicos y las consecuencias de esta utilización. Dicho de otro modo, hay que situarse en el nivel de racionalidad R4 (racionalidad teleológica), sin pasar por R3 (racionalidad pragmática).

Éste es el punto de vista de Liborio HIERRO ${ }^{19}$ en su importante monografía dedicada a la eficacia de las normas jurídicas. Junto a la eficacia como cumplimiento (con sus variantes, según el motivo que mueve al sujeto) y como aplicación, la eficacia como "éxito" ${ }^{20}$. Para la medición del éxito hay que «seleccionar una definición adecuada de los propósitos del legislador y reconstruir el estado de cosas previo a la edición de la norma y el alcanzado mediante el cumplimiento o la aplicación de la norma» ${ }^{21}$. Ahora bien, por lo que se refiere a la eficacia de las normas permisivas (y entendidos los permisos como "permisos completos", que facultan al destinatario para realizar o no realizar la acción), no cabe hablar de correspondencia, ni de cumplimiento, ni de aplicación. «Sin embargo, los permisos pueden ser eficaces o ineficaces en el preciso sentido de que pueden tener o no tener éxito. Los permisos se dan para algo» ${ }^{22}$. El

19 HIERRO, 2003.

${ }^{20}$ Sobre la terminología, HiERro, 2003: p. 160 (nota 17); en p. 74, un esquema con los diferentes sentidos de eficacia de las normas jurídicas. Esta concepción de la eficacia como éxito podemos considerarla propia de la sociología jurídica. El punto de vista estricto de la eficacia como cumplimiento (o, caso de incumplimiento, aplicación) es más propio de la teoría del Derecho, centrada, en lo que aquí concierne, en el problema de la necesidad de algún tipo de eficacia de las normas como requisito para la existencia de las mismas o, como más generalmente se piensa, de los ordenamientos jurídicos. Como advierte HIERRO al poner de manifiesto la ventaja de las investigaciones sociológicas sobre el éxito de las normas, «no hay ninguna demanda teórica que haga depender la existencia o validez de las normas o la existencia de un sistema jurídico de que el legislador consiga alcanzar mejor o peor sus propósitos» (p. 168).

${ }^{21}$ Hierro, 2003: p. 168. Además, han de tenerse en cuenta, para descontarlos de la eficacia, los efectos colaterales no deseados, en particular los efectos perversos.

${ }^{22}$ Hierro, 2003: p. 174. Los enunciados normativos de permisión ("permisos fuertes" en el sentido de AlchourRon y Bulygin, para distinguirlos de la mera ausencia en el sistema de normas de mandato sobre aquella conducta) contribuyen a guiar la conducta de los destinatarios de las normas. Como explican ATIENZA y Ruiz MANERo (2004: p. 130), «el hecho de saber con certeza que un determinado comportamiento es facultativo —esto es, que está libre de restricciones normativas — hará sin duda que muchos empiecen a hacer (...) lo que en otro caso no harían». Ejemplos para civilistas: arts. 1.323 y 1.326 CC (sin ellos, en ausencia de prohibición, los cónyuges podrían hacer lo que ellos indican, pero acaso no habría seguridad). Más claro aún: art. 1.458 CC, sobre el que se dice en la Memoria del Borrador de Anteproyecto de Ley de modificación del Código civil en materia de contrato de compraventa (Boletín de Información del Ministerio de Justicia, 1 de mayo de 2005, n. ${ }^{\circ} 1.988$, p. 2079) que «ha sido suprimido, porque en el momento actual resulta innecesario advertir que el marido y la mujer pueden venderse bienes recíprocamente». 
grado de utilización de los permisos serviría de indicador del éxito de la norma y, en este sentido, de su eficacia.

HIERRO pone dos ejemplos. El primero se refiere a la introducción del divorcio por la Ley de 7 de julio de 1981 y su éxito vendría indicado por el «índice de conflictividad matrimonial». El segundo, a la posibilidad de celebrar contratos de trabajo a tiempo parcial de acuerdo con el RD-Ley 15/1998, de 27 de noviembre. Ocurrió que el porcentaje de contratos a tiempo parcial bajó del 20,3 en 1998 al 18,7 en 1999. En consecuencia, según HIERRO, «cabe afirmar que la ley no tuvo éxito, al menos en ese primer año».

De estos ejemplos me interesan aquí dos observaciones:

a) Los ejemplos (divorcio, contrato de trabajo) no se refieren a meros permisos, sino a normas que atribuyen poderes. No me parece incorrecto. Por el contrario, creo que las normas de competencia (especialmente las de Derecho privado) pueden analizarse junto con las permisivas por lo que se refiere a su eficacia.

b) Los ejemplos sugieren que la actitud del legislador respecto de las normas de permisión no es siempre la misma. Tampoco parece igual la actitud de la sociedad ante la frecuencia de uso de los permisos.

De las normas permisivas y de competencia en el Derecho privado puede decirse que su función, en general, es ofrecer a los sujetos una posibilidad de alcanzar la satisfacción de sus intereses mediante acciones que no están prohibidas ni son obligatorias. En las normas de competencia, el legislador ofrece un instrumento mediante el cual los sujetos pueden producir resultados institucionales acordes con sus intereses. Motivan y guían la conducta de los sujetos en cuanto que éstos, si, movidos por sus deseos, pretenden alcanzar determinados resultados institucionales, habrán de comportarse como dispone la norma.

La actitud del legislador puede ser de indiferencia ante estos deseos e intereses de los particulares y las acciones (naturales o institucionales) necesarias para satisfacerlos (en efecto, ni las ordena ni las prohíbe), pero siempre tras una valoración positiva en cuanto a que, en abstracto, merecen la protección del derecho. Si nadie realiza nunca las acciones permitidas y, en particular, si nadie ejercita nunca los poderes conferidos, lo menos que puede decirse (admitiendo excepciones, como se verá) es que el legislador se ha equivocado en sus apreciaciones sobre los deseos e intereses de los ciudadanos y que ha hecho un trabajo inútil.

Dentro de esta actitud básica de indiferencia por parte del legislador, conviene todavía distinguir. En una dirección (que llamaré, para entendernos, permiso como tolerancia), parece que en ocasiones el legislador permite, por así decir, como mal menor y como deseando que, en realidad, nadie haga uso de la permisión, o cuanto menos posible. ¿Sería éste el caso del divorcio? Parece que es así en aquellas leyes de otros países que contienen instrumentos explícitos para retrasar la decisión de los cónyuges, imponerles mayor reflexión y ayudarles, si es posible, al mantenimiento de su matrimonio. Quizás era así —aunque la ley no era tampoco muy expresiva al respecto- en la ley española de 1981. Evidentemente, no lo es en la de 2005.

Ejemplos de permisos como tolerancia quizás sean las sustituciones fideicomisarias, o la posibilidad de pagar la legítima en dinero en ciertos casos, o la de conmutación del usufructo vidual. 
En la otra dirección (que llamaré permiso incentivado) hay sin duda permisiones que el legislador ve como de ejercicio deseable. Un ejemplo claro es el de la constitución de patrimonio especial para las personas con discapacidad ${ }^{23}$, incentivado fiscalmente en la misma ley que establece su posibilidad. Me parece significativo, y que abona la conveniencia de la distinción que estoy explicando, que no pueda decirse lo mismo de la permisión de constituir una sustitución fideicomisaria en perjuicio de la legítima de otros descendientes, de acuerdo con las innovaciones introducidas en los arts. 782 y 808 CC (permisión que, ciertamente, carece de incentivos específicos) ${ }^{24}$. En medio quedarían los "simples" permisos.

En todos los supuestos, la eficacia social de la norma de permisión requiere cierto número de acciones correspondientes a la norma, de manera que a mayor número de acciones correspondientes mayor es la eficacia de la norma. Cuántas acciones se requieran para que podamos decir que la norma es más bien eficaz que ineficaz, no es cosa fácil de decir. Pero recuérdese que tampoco es fácil — quizás imposible— cuantificar el número de actos de cumplimiento (o, en su caso, de aplicación) para poder afirmar la eficacia de una norma de mandato ${ }^{25}$. Lo mismo que respecto de éstas, un parámetro lo da el número de casos posibles, es decir, los incluidos en el ámbito de aplicación (interna) o de validez, si se prefiere, según los criterios materiales, personales, territoriales y temporales. Para las normas de mandato se ha propuesto una definición de "eficacia como mayoría" del siguiente tenor: «Una norma general $(\mathrm{N})$ es eficaz si y sólo si la mayoría de los sujetos en la mayoría de las ocasiones no infringen a $(\mathrm{N})$ » (NAVARRO, 1990: 23). Para las de permisión, es evidente que una proporción de acciones (coincidentes con el permiso) muy inferior al de la mayoría de los casos posibles sería suficiente para afirmar la eficacia, y que la proporción ha de variar de acuerdo con los tipos de permisión que a estos efectos he distinguido: mayor, obviamente, en el permiso incentivado, y menor en el permiso-tolerancia. Pero aun en estos últimos debe darse algún caso, pues de otro modo el legislador ha fallado en su previsión sobre los deseos y motivaciones de los ciudadanos. Lo superfluo es erróneo.

De esta manera podremos valorar la eficacia de normas que, por ejemplo: instauran determinados registros, o permiten la inscripción de ciertos actos en registros preexistentes, y nadie o muy pocos acuden a inscribir; permiten el testamento mancomunado o los pactos sucesorios para la transmisión de determinadas explotaciones agrarias, y muy pocos utilizan estos instrumentos; permiten el nombramiento de tutor por determinados parientes o en determinados casos, o la autotutela, o la tutela por

${ }^{23}$ Ley 41/2003, de 18 de noviembre, de protección patrimonial a las personas con discapacidad y de modificación del Código civil, de la Ley de Enjuiciamiento Civil y de la normativa tributaria con esta finalidad.

${ }^{24}$ Un claro ejemplo de permiso incentivado es el permiso laboral a favor del padre trabajador en caso de parto. La Ley que modifica el art. 48.4 ET, llamada de «conciliación de la vida familiar y laboral» (Ley 39/1999, de 5 de noviembre), en su Disp. Ad. 4. ${ }^{\text {, }}$, manifiesta el propósito de los poderes públicos de «conseguir que se acojan a las nuevas posibilidades» las trabajadoras y los trabajadores. Los incentivos no han modificado sensiblemente las preferencias de los ciudadanos, de modo que el legislador, decidido a lograr la consecución de ciertos fines, tiempo después se plantea hacer obligatorio el "permiso" del padre.

25 Tras un cuidadoso estudio de la cuestión, en particular de las propuestas de NAVARRO, L., HiERro concluye (p. 137): «No hay criterio alguno de carácter general que permita una medida común del cumplimiento de las normas jurídicas que pueda resultar significativa» (lo que no significa que hayamos de renunciar a medir la eficacia social de las normas). 
parte de personas jurídicas (aquí las variantes de la realidad son muchas y el estudio empírico sin duda muy interesante); permiten la emancipación por concesión (de los padres o del juez) o por matrimonio; permiten la constitución de patrimonios especiales para personas con discapacidad, cuya eficacia, en el sentido dicho, habrá que ver. Los ejemplos pueden multiplicarse, pues toda norma permisiva es susceptible de un análisis en el que se compare el universo de casos posibles y la proporción en que el legislador prevé que la norma será utilizada con el número de los actos realmente realizados.

Después de todo, quizás la diferencia con el criterio de eficacia de las normas de mandato sea que la previsión del legislador es, respecto de éstas, que la acción (cumplir) la realicen todos los que se encuentren en la situación de aplicación de la norma; mientras que en las permisivas la previsión es que la acción correspondiente la realicen quienes quieran (de acuerdo con sus propios motivos o además incentivados por el legislador) ${ }^{26}$.

El análisis de eficacia de las normas que conceden permisos o confieren poderes puede llegar mucho más lejos que estas consideraciones puramente indicativas. Lo que me importaba era mostrar que el análisis de eficacia es pertinente y útil también respecto de este tipo de normas, que constituyen la mayor parte de las correspondientes al Derecho civil.

Haré todavía un par de observaciones. La simple atribución de un poder produce ya efectos en la realidad, aunque el poder no se ejercite. Se ha puesto el ejemplo ${ }^{27}$ del poder conferido al presidente de gobierno de disolver el parlamento en ciertos supuestos: la sola potencialidad de la disolución incide en el comportamiento de los grupos parlamentarios. Poseer el arma puede ser incluso mejor que tener que utilizarla ${ }^{28}$.

De manera más general, la atribución de acciones judiciales (en definitiva, un tipo de poderes jurídicos) puede ser eficaz socialmente aunque nadie las ejercite o prescindiendo del número de casos en que realmente se ejercitan. Puede bastar con que se tengan (y los cauces procesales sean claros, y los resultados del proceso y de la eje-

${ }^{26}$ Hay un amplísimo campo jurídico ajeno totalmente a las normas de mandato que parece especialmente apto para el análisis de eficacia. Me refiero, precisamente, a ese campo creciente en intensidad e importancia de las leyes que establecen incentivos para la realización de conductas que no son obligatorias ni prohibidas, y que tienen una explícita finalidad de modificar la realidad social. Para profesores de Derecho, el caso de las normas de reconocimiento de sexenios en razón de investigación podría ser un estupendo campo de análisis sobre eficacia de las normas (incluidas las consideraciones sobre efectos imprevistos o indeseados) y para afinar los conceptos correspondientes. Si ningún profesor hubiera hecho evaluar sus trabajos (y ninguna obligación había), creo que la calificación de fracaso total sería inapelable. Yendo las cosas como van, y suponiendo que se presentan a la evaluación la inmensa mayor parte de los que están en el campo de aplicación de la ley, la eficacia en este sentido es indudable. Estaríamos en el nivel R3 de la clasificación de ATIENZA. Reflexiones mucho más complejas se presentarían en el nivel R4 (¿cómo ha contribuido el sistema a elevar la calidad de la investigación académica en España?).

${ }^{27}$ No puedo recordar dónde lo he leído. Sirva esta nota de reconocimiento a su autor.

${ }^{28}$ Cabe pensar que algunos poderes es mejor que no haya que usarlos, por lo que la eficacia de las normas que los atribuyen no puede medirse en ningún caso por la frecuencia con que se usen. Puede ser el caso de la desheredación (en que las normas tienen también un aspecto simbólico nada desdeñable). Otro ejemplo podría ser la llamada aceptación de la herencia por los acreedores. Pocas veces se habrá ejercitado —-supongo, pues en este como en casi todos lo demás ejemplos que voy poniendo no hay estudios empíricos-, pero es de suponer que su sola posibilidad, conocida por el llamado a la herencia, evite en muchos casos que deudores insolventes renuncien a la herencia sin otro fin que perjudicar a sus acreedores. 
cución seguros) para que la conducta de los posibles demandados se atenga a las normas, sin necesidad de pleito. El análisis de la eficacia de las normas procesales es un mundo por sí mismo, en el que aquí no hemos de entrar.

\section{LAS NORMAS DISPOSITIVAS}

\subsection{Concepto de norma dispositiva}

La caracterización de las normas civiles dispositivas o supletorias (ius dispositivum) no es tan segura como sería de desear. Las analizaré como el resultado del juego de dos normas ${ }^{29}$ : a) una norma $\mathrm{N}_{1}$, que proporciona el contenido normativo y que puede ser de cualquier clase (de mandato, de permisión, atributiva de poderes, constitutiva, conceptual); $b$ ) otra norma $\mathrm{N}_{2}$ que atribuye el poder de desplazar a $\mathrm{N}_{1}$ excluyendo su aplicación en ciertos casos y bajo ciertas condiciones ${ }^{30}$.

${ }^{29}$ En los análisis especializados sobre "normas dispositivas" se hace referencia habitualmente al juego de dos normas. Ocurre así en el trabajo de BüLow en 1881 (que puede considerarse pionero en la dogmática contemporánea), si bien con la terminología cambiada (y quizás más adecuada). Las normas dispositivas (dispositives, nachgiebiges, vermittelndes Recht), a diferencia de las de derecho necesario o cogente (absolutes, zwingendes Recht, que señalan las consecuencias ineludibles de un supuesto de hecho), atribuyen a los interesados el poder de regular la relación jurídica dentro de ciertos límites (p. 9). «Normas dispositivas» son para BÜLOW, por tanto, las normas que atribuyen poderes (BÜLOW no utiliza exactamente esta terminología, aunque sí varias veces la palabra Macht y sus derivados). A estas normas acompañan de ordinario las subsidiarias o complementarias (p. 71: «In Gefolge der dispositiven Rechtsnormirung findet sich oft eine subsidiäre, ergänzende Rechtsregelung vor») (VON BÜLOW, 1881: «Dispositives Civilprocessrecht und die verbindliche Kraft der Rechtsornung», Archiv für die Civilistishe Praxis, 64, pp. 1-109; ENNECCERUs, 1889: Rechtsgeschäft, Bedingung und Anfangtermin, Marbur, pp. 152-160; EHRLICH, E., 1899, Das zwingende und nichtzwingende Recht im Bügerlichen Gesetzbuch für das deustche Reich, Jena, repr. facsimilar, Aalen: Scientia Verlag, 1970; FRÖHLICH, E., 1922: Von zwingenden und nichtzwingenden Privatrecht, Aarau, en obras generales traducidas al castellano, Von Tuhr, I, 1: pp. 32-35 y, sobre todo, EnNeCCERUS, I, 1: pp. 183-187. De CASTRO no considera muy relevante la distinción entre normas imperativas y dispositivas y está más preocupado por reconocer también a éstas cierto carácter imperativo que por explicar qué sean unas y otras. Acierta al advertir que «no se trata de un tipo de normas [las dispositivas] por su naturaleza, sino que, por el contrario, será la mayor o menor independencia que se dé a la voluntad la que señale el carácter de la regla» (DE CASTRO, F., 1949: Derecho civil de España, Parte General, t. I, Madrid: Instituto de Estudios Políticos, 2. ${ }^{a}$ ed., repr. facsimilar de Civitas, Madrid, 1984, pp. 55-56; cfr. p. 534). En CASTÁN, por el contrario, puede encontrarse una sencilla exposición que se atiene a las concepciones más extendidas al clasificar las normas «por su eficacia frente a la voluntad de los particulares». A las normas imperativas denomina también Derecho absoluto, necesario, impositivo (ius cogens), las relaciona con el orden público y las divide en preceptivas y prohibitivas. A las otras las llama permisivas (y Derecho voluntario, facultativo, supletorio, dispositivo, ius dispositivum), las relaciona con el interés privado y las divide en interpretativas e integrativas (supletorias, integradoras) (CASTÁN TOBEÑAS, J., 1982: Derecho civil español, común y foral. T. I, Introducción y Parte General, vol. 1, Ideas generales. Teoría de la norma jurídica, Madrid: Reus, S. A., pp. 403-406. Fuera de los tratados generales, merece destacarse la aportación de Díez-Picazo (Díez-Picazo y PonCE DE León, L., 1956: «La autonomía privada y el derecho necesario en la Ley de Arrendamientos Urbanos», $A D C$, IV, pp. 1147-1181, con una exposición clara y equilibrada de las relaciones entre la autonomía privada y las normas imperativas o dispositivas, si bien la total ausencia de referencias bibliográficas dificulta situar sus reflexiones en las corrientes de la civilística española y europea (algunas indicaciones proporciona el autor en obra de las mismas fechas, 1956: «Los llamados contratos forzosos», $A D C$, I, pp. 85-118).

${ }^{30}$ Con este análisis de las normas dispositivas pueden hacerse algunas observaciones útiles sobre el sentido o los sentidos en que puede decirse que tales normas son también, a pesar de todo, "imperativas". Por una parte, lo son (en el sentido de que obligan o prohíben) cuando la norma $\mathrm{N}_{1}$ es regulativa de mandato y no se ha ejercido el poder conferido por la norma $\mathrm{N}_{2}$. Por otra, las condiciones de actualización del poder pueden ser distintas según variadas circunstancias (por ejemplo, contratación entre particulares en pie de igual- 
Habitualmente se llama norma dispositiva a $\mathrm{N}_{1}{ }^{31}$.

$\mathrm{N}_{2}$ puede representar una pluralidad de normas que confieren poderes en casos $\mathrm{y}$ en condiciones distintos.

La norma $\mathrm{N}_{2}$ puede conferir un poder tal que se dirija directa y simplemente a la exclusión de la aplicación de la norma $\mathrm{N}_{1}$ sin necesidad de que el sujeto proporcione otra regulación: por ejemplo, así puede operar la exclusión de las normas sobre responsabilidad para el caso de evicción en la compraventa.

En otros casos el sujeto o los sujetos han de producir una autorregulación que sustituya a las reglas estatales. Así ocurre respecto de las normas de régimen de gananciales (es preciso para excluirlas un régimen matrimonial pactado) o las de sucesión abintestato (es preciso cierto contenido testamentario). En general, si la autorregulación es insuficiente, se aplicará la norma $N_{1}$ que no haya sido válidamente excluida.

Ser "norma dispositiva" no es una propiedad intrínseca de $\mathrm{N}_{1}$, sino una "propiedad relacional" ${ }^{2}$. Es más bien el resultado del juego conjunto de $\mathrm{N}_{1}$ y $\mathrm{N}_{2}: \mathrm{N}_{1}$ es "norma dispositiva" gracias a la existencia de $\mathrm{N}_{2}$. Y la propiedad de $\mathrm{N}_{1}$ de ser norma dispositiva es relativa también en el sentido de que, puesto que pueden existir varias $\mathrm{N}_{2}$, $\mathrm{N}_{1}$ puede ser desplazada por procedimientos y con requisitos distintos según los casos ${ }^{33}$.

El mandato ${ }^{34}$ de $\mathrm{N}_{1}$ sólo se actualiza cuando, en el caso, no se ha hecho uso del poder conferido por $\mathrm{N}_{2}{ }^{35}$. Por tanto, la función genérica de la norma dispositiva $\left(\mathrm{N}_{1}\right)$ en cuanto tal es proporcionar una regla en defecto de un acto de autonomía.

La eficacia de $\mathrm{N}_{1}$, cuando no se ejercita el poder conferido por $\mathrm{N}_{2}$, se aprecia del mismo modo que la de cualquier otra norma de mandato (de permiso, de poder...), de acuerdo con los criterios hasta ahora expuestos.

A su vez, la eficacia de $\mathrm{N}_{2}$ podría medirse como la de cualquier norma de atribución de poder. En realidad, muchas (acaso la mayor parte) de las normas que confie-

dad, condiciones generales de la contratación), de manera que en unos casos puede excluirse la norma $\mathrm{N}_{1}$ y en otros no: cuando la norma $N_{1}$ no puede excluirse podemos decir que estamos en presencia de una "norma imperativa". Pero no es que la norma $\mathrm{N}_{1}$ cambie de naturaleza, o la tenga plural, sino que la diferencia reside en las condiciones del poder conferido por la norma $\mathrm{N}_{2}$ en relación con el caso. Dicho de otro modo, ser "dispositiva" no denota una propiedad de la norma N1, sino la función subsidiaria o complementaria que puede tener en relación con el ejercicio del poder conferido por la norma $\mathrm{N}_{2}$. Y en todos los casos las normas son "vinculantes", "obligatorias", en el sentido de que son verdaderas normas jurídicas a las que los particulares están sujetos: tanto la norma $\mathrm{N}_{2}$ (que atribuye el poder al particular) como la $\mathrm{N}_{1}$, que se aplica en todos los casos previstos por el ordenamiento.

${ }^{31}$ BÜlLOW denominó "norma dispositiva" a $\mathrm{N}_{2}$, poniendo así en la pista del juego conjunto de $\mathrm{N}_{1}$ y $\mathrm{N}_{2}$ que los autores posteriores advirtieron y explicaron con mayor o menor claridad.

32 En el sentido, por ejemplo, de que nadie es intrínsecamente "primo hermano", sino en relación a otros sujetos a los que les une determinado grado de parentesco.

33 Lo anterior explica o, al menos, permite plantear correctamente, el fenómeno de que una misma norma $\mathrm{N}_{1}$ que, en general, resulta dispositiva para los contratantes, pueda ser "imperativa" (ius cogens) cuando la materia se regula mediante condiciones generales. También que $\mathrm{N}_{1}$ pueda ser desplazada sólo cuando la regulación contenida en $\mathrm{N}_{2}$ favorezca a determinado sujeto, que el legislador considera típicamente más vulnerable o necesitado de protección (por ej., contrato de trabajo, arrendamientos urbanos, contratación con consumidores).

${ }^{34} \mathrm{O}$ el permiso, o el poder conferido, o la definición propuesta.

${ }^{35}$ En lo que sigue, el poder conferido por $\mathrm{N}_{2}$ se interpretará como poder de autonomía privada. 
ren poderes en Derecho privado están relacionadas con normas "dispositivas", que disciplinan la situación para el caso de no ejercicio del poder.

Pero no es el análisis, por separado, de la eficacia de $\mathrm{N}_{1}$ y de $\mathrm{N}_{2}$ el que nos ilustrará sobre la eficacia específica de las normas dispositivas. Si lo característico de éstas es el juego conjunto de $\mathrm{N}_{1}$ y $\mathrm{N}_{2}$, en este juego conjunto habremos de centrarnos para apreciar su eficacia social.

\subsection{Eficacia social y ejercicio del poder de desplazar la norma}

Podemos comenzar con una pregunta: ¿Son más eficaces las normas dispositivas $\left(\mathrm{N}_{1}\right)$ cuando se aplican siempre, o en el mayor número de casos, por no ejercer los sujetos el poder conferido por $\mathrm{N}_{2}$ ? ¿ $\mathrm{O}$, por el contrario, son más eficaces cuanto menos se hayan de aplicar por ser excluidas en la mayor parte de los casos mediante el poder conferido por $\mathrm{N}_{2}$ ?

A preferir la primera alternativa llevaría acaso un prejuicio contrario a la autonomía privada, entendida como mal menor y desviación simplemente tolerada de las reglas legales; mientras que la afirmación de la primacía de la autonomía privada conduciría a la segunda alternativa.

Pero las cosas no son así de simples. En el primer caso, ¿por qué habría de molestarse el legislador en dictar normas dispositivas? Le bastaría y sería preferible convertir en cogentes las dispositivas o prescindir de ellas. En el segundo caso, estaríamos olvidando los costes de transacción. Es imposible para los contratantes prever todas las circunstancias, contingencias y vicisitudes posibles de su relación contractual; antes que imposible, es costoso en información, tiempo y esfuerzo y, por tanto, ineficiente el tratar de prever las consecuencias más allá de ciertos límites. Las normas dispositivas son, por tanto, funcionales a la libertad de contratación, al facilitar (abaratar) las transacciones, proporcionando un regla para los supuestos que los contratantes no han podido o querido prever. De manera que también desde este punto de vista parece de mayor eficacia la norma dispositiva que no es excluida por voluntad de los particulares, pues esto es comprobación o, al menos, indicio, de que la consideran adecuada para regular sus incumbencias.

Sin embargo, parece necesario distinguir tipos de normas dispositivas, atendiendo a la función específica de cada una de ellas, antes de formular algún juicio sobre su eficacia social.

No hay que atender sólo al contenido de la norma $\mathrm{N}_{1}$, sino también al tipo de permiso que acompaña a la norma $\mathrm{N}_{2}$. El poder de ejercicio facultativo de darse normas distintas de $\mathrm{N}_{1}$, desplazando la aplicación de ésta, puede ser, como todos los permisos, de mera tolerancia, neutro o incentivado. El éxito de las normas dispositivas puede consistir tanto en su aplicación en la mayor parte de los casos posibles como en que no se vean aplicadas prácticamente en ningún caso: dependerá del sentido del permiso.

En cualquier caso, el concepto de eficacia se aleja notablemente de la elemental apreciación del cumplimiento de la norma (o, en otro caso, aplicación coactiva). Es evidente que la exclusión de la norma $\mathrm{N}_{1}$ mediante el ejercicio del poder conferido por la norma $\mathrm{N}_{2}$ no es un supuesto de incumplimiento de $\mathrm{N}_{1}$. 
Haré primero algunas consideraciones sobre normas dispositivas ajenas a la materia contractual y luego sobre las que se insertan en la regulación del contrato o de los contratos en particular.

\subsection{Las normas sobre sucesión intestada}

En primer lugar, los importantes supuestos de la sucesión intestada y del régimen económico matrimonial. Estas normas son dispositivas, puesto que su aplicación puede ser evitada mediante el testamento, en el primer caso, y las capitulaciones matrimoniales, en el segundo. Pero, a diferencia de lo que ocurre respecto de las normas contractuales dispositivas, que sólo están llamadas a aplicarse en presencia de un contrato y para completar sus reglas, la sucesión intestada o el régimen matrimonial legal rigen en ausencia de toda previsión de los particulares cuando se dan ciertos hechos: involuntario en el primer caso —-muerte del causante-, voluntario en el segundo —-matrimonio.

En ambos casos, conocer el número o proporción de actos de los particulares que excluyen las normas dispositivas parece relevante para juzgar sobre la eficacia de éstas, en el sentido de la utilidad y utilización reales de los poderes atribuidos a los particulares y de la capacidad de las normas dispositivas para conformar las relaciones sociales.

¿Cuántas sucesiones, en España, se gobiernan por las normas — dispositivas— de la sucesión intestada y cuántas por testamento? ¿Más o menos que en los países de nuestro entorno? ¿Crece o disminuye el número de testamentos?

No es fácil contestar. Traté de hacerlo en otro trabajo ${ }^{36}$, apurando al máximo los datos publicados - procedentes de la estadística notarial —, con el apoyo de un escandallo que amablemente realizaron los funcionarios de la Dirección General de Tributos del Gobierno de Aragón durante cuatro meses. Aunque nuevas comprobaciones serían muy convenientes, creo poder afirmar que, en España, aproximadamente la mitad de todas las herencias se defieren por testamento. Con toda seguridad, el número de testamentos otorgados en los últimos veinte años aumenta sorprendentemente: desde 1984 ha crecido más del $50 \%$, lo que no sólo es muy superior al aumento de la población, sino también al incremento del total de instrumentos notariales autorizados. Si los datos son ciertos, España sería uno de los países del mundo con mayor número de herencias deferidas por testamento, quizás por encima de Estados Unidos, que suele considerarse a la cabeza de la libertad de testar y su ejercicio ${ }^{37}$. Para Europa, se considera que en Inglaterra el porcentaje llega al 30\%, en Alemania quizás al 20, y puede bajar hasta el 2,5 en Italia ${ }^{38}$.

${ }^{36}$ Delgado, J., 2006: «Una propuesta de política del Derecho en materia de sucesiones por causa de muerte», Derecho de sucesiones. Presente y futuro. XII Jornadas de la Asociación de Profesores de Derecho Civil, Santander 9 a 11 de febrero de 2006, Servicio de Publicaciones, Universidad de Murcia, pp. 103-115.

37 Van Houtte, J.; Keuleneer, M., y Van Der Brande, K., 1995: «Inheritance Law and Practice in the USA and Belgium», Sociologia del Diritto, n. 3, pp. 75-106.

${ }^{38}$ FERRARI, V., 1972: Succesione per testamento e trasformazioni sociali, Milano: Edizione di Communità, p. 75 . 
Si los datos son ciertos — por segunda vez introduzco esta cautela, dadas las dificultades para averiguarlos - es claro que, en España, las normas — dispositivas- sobre sucesión intestada son mucho menos eficaces que en otros países, en el sentido de que son seguidas en un número menor de los casos posibles. ¿Es ello de lamentar? Antes al contrario, si consideramos la libertad testamentaria como un principio valioso. Pero, dejando aparte otras muchas consideraciones posibles — sobre la afortunada configuración por la ley del testamento notarial y su fiabilidad, por ejemplo; o sobre la influencia en la testamentifacción del acceso generalizado a la propiedad de la vivienda-, hay un aspecto que merece la pena señalar. Se ha sugerido (ciertamente, para otros países europeos) que «la propensión a testar depende en buena medida de la opinión social sobre el ordo succesorius legal» ${ }^{39}$, o bien que «si las concepciones de la ley de sucesión intestada no coinciden con las de la gente, habrá mayor propensión a hacer testamento» ${ }^{40}$. Fluye fácil la hipótesis de que, en el ámbito del Código civil español, el deseo de las personas casadas de dejar al cónyuge bastante más de lo que la ley le atribuiría abintestato (en concurrencia con descendientes o con ascendientes) es uno de los mayores estímulos para otorgar testamento. Si esto es así, bien podría decirse que las normas que regulan la sucesión intestada tienen un déficit de eficacia social porque se apartan, al menos en el punto señalado, de lo que los ciudadanos entienden que debería ser el curso del fenómeno sucesorio.

\subsection{Las normas sobre régimen económico matrimonial}

Echemos ahora una ojeada a lo que ocurre con las capitulaciones matrimoniales. En la tradición del Código civil español eran muy escasas las capitulaciones matrimoniales anteriores al matrimonio y estaban prohibidas las posteriores (hasta 1975). Por el contrario, en los Derechos civiles forales tuvieron históricamente las capitulaciones un papel central en la regulación de las relaciones económicas en la familia. Ahora bien, en la segunda mitad del siglo XX su otorgamiento llegó a ser un fenómeno marginal, relacionado con formas tradicionales agrarias de familia. En definitiva, apenas había diferencia dentro de España en cuanto a otorgamiento de capitulaciones matrimoniales, que en todos los lugares era muy escaso, aunque todavía algo mayor en los países de fuero.

Pues bien, en los últimos tiempos está ocurriendo algo notable. El número de capitulaciones otorgadas aumenta desde 1975, hasta llegar en el año 2001 al 30\% del número de matrimonios contraídos en el mismo año (en 1975 era del $0,8 \%$ de los matrimonios contraídos en el mismo). Por otra parte, este aumento es bastante homogéneo o, en todo caso, no responde a los viejos esquemas de contraposición entre Código civil y Derechos forales. Canarias y Madrid están a la cabeza. Sin duda divorcios y segundos matrimonios proporcionan estímulos para capitular, sentidos en principio del mismo modo en el centro que en la periferia, en el norte que en sur (con la importante excepción que se comenta a continuación). Parece que un creciente número de matrimonios no se encuentran a gusto bajos las reglas del régimen económico matrimonial legal. El desapego a la comunidad de gananciales, aunque minoritario, es ya

\footnotetext{
39 FERRARI, V., 1972: p. 51.

${ }^{40}$ Van HooutTe y otros, 1995: p. 85.
} 
claramente visible en la sociedad. Es el régimen de separación el que se considera preferible en muchos casos.

Confirmación de esta preferencia por el régimen de separación nos la proporciona el hecho, de otro modo incomprensible, del aumento mucho menor que las capitulaciones matrimoniales han experimentado en Cataluña, tierra tradicional de ellas. Lo que ocurre es que el régimen legal es allí el de separación y prácticamente nadie pacta uno de comunidad: las capitulaciones parecer servir allí preferentemente para modificar algunos rasgos del régimen de separación recientemente innovados por el legislador ${ }^{41}$.

Podríamos concluir diciendo que, comparativamente, las normas del Código civil sobre comunidad de gananciales son menos utilizadas por sus destinatarios como modelo para orientar sus conductas que hace unos decenios; y menos también que las catalanas sobre régimen de separación por los suyos.

Por último, una observación sobre las reglas del "régimen de participación" introducidas en el Código civil en 1981 (arts. 1.411-1.434). Puesto que prácticamente nadie ha pactado desde entonces tal régimen — no se conocen resoluciones judiciales sobre el mismo- bien puede concluirse que son reglas dispositivas totalmente ineficaces: una oferta legal de normas dispositivas que no ha encontrado ninguna aceptación.

\subsection{Derecho de los contratos}

Pasemos al Derecho de los contratos, en el que el Derecho dispositivo ocupa la mayor parte de los artículos de los códigos. Los autores mantienen distintas concepciones sobre la finalidad y sentido de las normas dispositivas. La opinión más antigua las entendía como expresión de la "voluntad presunta" de los contratantes; luego, como "voluntad hipotética", o más bien como la regulación que dos sujetos racionales - que disponen de toda la información y ninguno de ellos tiene poder sobre el otro- habrían dado ex ante si hubieran dedicado la atención suficiente a aquellas incidencias posibles. Por otra parte, está la opinión (quizás no tan alejada de la última indicada) de quienes entienden las normas dispositivas como la regulación justa discernida por el legislador en atención a los intereses en juego en un particular tipo contractual. Además, se admite con mayor o menor amplitud que las normas dispositivas pueden o deben recoger los usos del tráfico o acomodarse a ellos.

EHRLICH ${ }^{42}$ sugirió que la función principal de todas las normas dispositivas (nichtzwingende Recht) es evitar o limitar el arbitrio judicial, proporcionando una norma cierta

${ }^{41}$ Para todo lo anterior, LAMARCA, A., y otros, «Separación de bienes y autonomía privada familiar en Cataluña», Indret, 4/2003, en línea en http://www.indret.com/pdf/dc07 es.pdf (consultado 22 de enero de 2006); luego en «Separate property and family self-determination in Catalonia: A changing model?», en MARTíNCASALS, M., у Rовот, J. (eds.), 2006: The role of self-determination in the modernisation of family law in Europa, Girona: Documenta Universitaria (con datos actualizados hasta 2003). Datos sobre capítulos matrimoniales y régimen de separación pactados por contrayentes en Zaragoza el año 2002, anotados en el Registro civil inmediatamente antes o después, en LACRUZ MANTECÓN, M., 2004: intervención en la Ponencia «El régimen económico matrimonial de separación de bienes», Actas de los decimoterceros Encuentros del Foro de Derecho Aragonés, Zaragoza: El Justicia de Aragón, pp. 146 y ss.

${ }_{42}$ EHRLICH, E., 1899: Das zwingende und nichtzwingende Recht im Bügerlichen Gesetzbuch für das deustche Reich, Jena, repr. facsimilar, Aalen: Scientia Verlag, 1970, p. 42. En pp. 74, un cuadro de las posi- 
para todos los supuestos que los contratantes no quisieron o no pudieron prever. A estos efectos, es irrelevante el contenido de la norma dispositiva: lo importante es que ha de ser aplicada por el juez por igual a todos los casos iguales. Podemos luego - EHRLICH lo hace- diferenciar diversos tipos o grupos de normas dispositivas, pero para todas ellas, cualesquiera que sean sus otros fines (interpretar la voluntad de las partes, recoger las cláusulas frecuentes en contratos del mismo tipo, adoptar los usos del tráfico, introducir una regulación equilibrada respecto de los intereses de las partes típicamente considerados, proteger a una de las partes), lo principal es que exista esa norma dispositiva que el juez ha de aplicar (necesariamente: para el juez es norma cogente).

Partiendo de esta idea de EHRLICH, que me parece clarificadora, el análisis podría continuar sugiriendo la irrelevancia o indiferencia de los contenidos específicos de las normas dispositivas. Puesto que los particulares pueden evitarlas, cualquier contenido sería adecuado ${ }^{43}$, también el más alejado de las previsiones y deseos típicos de los particulares. Aun así, parecería un fracaso de la obra del legislador si ocurriera que en la inmensa mayor parte de los casos en que las normas dispositivas podrían aplicarse los particulares las excluyeran ${ }^{44}$.

Pero hay más. El contenido de las normas dispositivas sería quizás indiferente en ausencia de costes de transacción. La mera existencia de la norma dispositiva (cualquiera que sea su contenido) ahorra costes de transacción. Ésta sería la principal función de estas normas de acuerdo con el análisis económico del Derecho ${ }^{45}$. Pero los contenidos específicos de estas normas, aun inadecuados (cualquiera que sea el punto de vista, subjetivo u objetivo, para este juicio), se impondrán en la realidad si son altos

bles funciones (el autor habla de Zweck in Rechte y de ratio iuris) que pueden tener las normas que completan el contenido de las declaraciones negociales de los particulares.

${ }^{43}$ Salvo que sea contrario a norma superior, en particular a la Constitución. De acuerdo con la importante STC de 14 de febrero de 2002, «no se derivan diferentes exigencias de adecuación constitucional según que la norma cuestionada tenga carácter dispositivo o imperativo. Al margen de que la posibilidad de que los particulares puedan desplazar la aplicación de la regulación dispositiva encuentra siempre determinados límites, en unas ocasiones generales y en otras acotados por la norma que establece tal posibilidad, no parece adecuado afirmar que no hacer uso del margen de autonomía reconocido en la norma implique una opción voluntaria de sometimiento a la regulación dispositivamente introducida en la norma, sino que la aplicación de la misma deriva del carácter vinculante del Derecho, por lo que las mismas exigencias de adecuación a la Constitución deberán entrar en juego».

${ }^{44}$ Creo que tal puede decirse, por ejemplo, de la norma que "presume" que no hay solidaridad entre deudores (art. 1.137 CC): en ningún contrato, al menos cuando una de las partes sea un profesional, dejará de pactarse la solidaridad. Dígase lo mismo de los llamados beneficios de excusión y división en la fianza; o de las normas que presume la gratuidad del préstamo de dinero (arts. 1.755 CC, 314 CCom.). Estas normas tienden a proteger al deudor, y su habitual ineficacia pone de manifiesto el escaso alcance práctico que tiene la pretensión de proteger a una de las partes de la relación mediante normas dispositivas.

${ }^{45}$ PaZ-Ares, C., 1995: «Principio de eficiencia y Derecho privado», Estudios en Homenaje a M. Broseta Pont, t. III, Valencia: Tirant lo Blanch, p. 2853 y referencias en nota 10, accesible en http://www.uam.es/centros/derecho/privado/mercanti/investigacion/ cpa\%20-\%20pop.pdf. El influyente artículo de AYRES, I., y GERTNER, R., 1989: «Filling Gaps in Incomplete Contracts: An Economic Theory of Default Rules», 99 Yale L. J., pp. 87 y ss. (que PAZ-ARES cita) introdujo el concepto de penalty default rules (normas dispositivas que pretenden mover a una de las partes a proporcionar información a la otra o a terceros), que autores posteriores aceptaron pero criticó Eric Posner (Posner, E., «There Are No Penalty Default Rules in Contract Law», U. Chicago Law and Economics, Olin Working Paper N. 237, accesible en SSRN: http://ssrn.com/abstract $=690403$. El estado de la cuestión en BAFFi, E., 2006: «Ayres and Gertner versus Posner-A Re-examination of the Theory of "Penalty Default Rules"》 (december), accesible en SSRN: http://ssrn.com/abstract $=948916$. 
los costes de transacción para pactar una regla que excluya la normas dispositiva. En este sentido, las normas dispositivas inadecuadas se aplicarán en buen número de casos en razón simplemente de los costes de transacción para evitarlas ${ }^{46}$.

Esto hace que el legislador pueda preferir determinados contenidos para regulaciones dispositivas, aun sabiendo o previendo que no serán recibidos con agrado por los particulares (puede creer que la regulación es más justa que la que éstos voluntariamente pactarían o dispondrían), sin verse compelido por ello a configurar la norma como imperativa (que parecería la opción obvia dadas las premisas). Le basta con prever que sólo una parte de los sujetos interesados harán uso del poder que les confiere para regular libremente sus relaciones, mientras que los otros, quizás la mayoría, por falta de información o, en general, por los fuertes costes de transacción a que habrían de enfrentarse, se verán de hecho sometidos a la norma. De este modo las normas dispositivas pueden tener (casi) la misma eficacia conformadora de las relaciones sociales que las normas imperativas.

\section{LAS NORMAS QUE INVALIDAN LOS ACTOS DE LOS PARTICULARES}

Las normas que confieren poderes a los particulares son simultáneamente normas que establecen los requisitos de validez de sus actos y, correlativamente, normas que señalan la invalidez de los que no se atengan a tales requisitos.

En cuanto que atribuyen poderes, guían u orientan conductas, aunque lo hagan de una manera distinta a las normas de mandato. Lo hacen indirectamente, se ha dicho ${ }^{47}$ : guían la conducta, no de todos aquellos que se encuentran en la situación hipotizada por las normas, sino únicamente de quienes tienen razones (deseos, intereses) para realizar con resultados institucionales el acto para el que se atribuye el poder.

En cuanto "normas invalidantes", quizás en un sentido muy amplio podría decirse que, lo mismo que las que establecen sanciones, contribuyen a «salvaguardar a las leyes de la erosión de las acciones contrarias» ${ }^{48}$. Éste es un importante efecto simbólico, que

46 Por ejemplo, cabe pensar que son altos los costes de transacción para pactar un régimen económico matrimonial distinto del legal, tanto antes como después del matrimonio. La situación es de monopolio bilateral.

47 RAZ, J., 1986: «Postscriptum», El concepto de sistema jurídico, trad. cast. México: UNAM, 272. ATIENZA y RuIZ MANERO traducen mejor el párrafo principal: «El Derecho guía la acción del titular del poder [...]. Es por esto por lo que las reglas que confieren poderes son normas. Guían la conducta. Pero a diferencia de las reglas que imponen deberes ellas proporcionan una guía indeterminada. Los deberes son exigencias que derrotan las otras razones para la acción que el agente tenga. La guía proporcionada por los poderes depende de las otras razones del agente. Si tiene razones para obtener el resultado que el poder le posibilita lograr, entonces tiene razones para ejercerlo. Si tiene razones para evitar el resultado, entonces tiene razones para no ejercer el poder» (AtienzA, M., y Ruiz Manero, J., 2004: Las piezas del Derecho. Teoría de los enunciados jurídi$\cos , 2^{\text {a }}$ ed., Barcelona: Ariel, p. 90.

48 Otra forma en que contribuyen las normas de (in)validez a mantener el respeto por el ordenamiento jurídico es mediante la legitimación específica que generan para la actividad y el poder de los juristas. De los tres tipos de actividad de los juristas romanos (cavere, agere, respondere), la primera, cavere, consiste en la redacción de la fórmula de los actos. No es casualidad que el conocimiento jurídico que Gneo Flavio "robó" a los pontífices para ponerlo a disposición de la plebe fuera precisamente el de las fórmulas procesales y para la validez de los actos en el ius. Hoy como ayer, los particulares (lo mismo que las autoridades) necesitan consultores jurídicos que les indiquen cómo realizar sus actos (contratos, testamentos, demandas) para que sean válidos. Adicionalmente, otros juristas (señaladamente, los notarios) han de intervenir en muchas ocasiones 
se produce por el simple hecho de existir la norma. Las normas de invalidez proclaman la "santidad de la ley", "santidad" que no quedará mancillada por los actos desviados de autoridades o particulares. Este efecto es automático, indefectible, sin necesidad de intervención de acto alguno de autoridad ni modificación en el mundo real. Por tanto, es gratis para el legislador y los poderes públicos, que no tienen necesidad de ninguna medida para implementar lo dispuesto en la norma. Gran tentación, por tanto, para el legislador, que puede creer que, con sus meras palabras ( «los actos de tal clase son nulos», con los añadidos, acaso, de «absolutamente, radicalmente, de pleno derecho») ya ha cambiado la realidad. Sin pensar en predisponer otras medidas (sanciones, por ejemplo) que disuadan eficazmente de realizar los actos, ni prever siquiera cómo orientará las conductas, en el caso concreto, la declaración de invalidez ${ }^{49}$.

En cierto sentido, las normas invalidantes son siempre eficaces: el acto «no produce efecto alguno». Pero esto sería una eficacia meramente "intrajurídica". La cuestión que nos planteamos es si la previsión normativa de la invalidez de los actos evita realmente la realización de los mismos. Si cumple una función disuasoria. En esto, en la posible función disuasoria, se parecería la invalidez a la sanción ${ }^{50}$.

Lo que sigue son algunas reflexiones sobre la posible eficacia disuasoria de las normas de invalidez.

1. No siempre las normas de nulidad pretenden disuadir de realizar los actos, o de realizarlos de otro modo que del predispuesto en las normas que regulan el ejercicio del poder. Al Estado puede serle indiferente que los particulares, por ejemplo, hagan testamentos o contratos inválidos por defecto de forma (le basta con no otorgarles validez). Nino lleva más lejos esta consideración y entiende que, en general, la nulidad no está dirigida a desalentar comportamientos disvaliosos ${ }^{51}$. En su opinión, en ausencia de normas prohibitivas (sobre modalidades de ejercicio del poder) «los particulares son completamente libres de celebrar los contratos jurídicamente nulos y de hacerlos cumplir por medios no coactivos». Hay que volver a subrayar la condición de «en ausen-

para "validar" los actos previa comprobación de su adecuación a la legalidad. Hipotéticamente, los miembros de una sociedad podrían prescindir de los juristas para el conocimiento de las normas de mandato, si éstas coinciden con las de la moral social; pero los necesitarán en cuanto las normas que confieren poderes señalen las modalidades para su ejercicio, pues éstas son siempre artificiales, "puramente jurídicas" y necesitadas de aprendizaje especializado.

${ }_{49}$ Es cómodo para los emperadores (Teodosio y Valentiniano, Lex Non dubium) fulminar con el rayo de la nulidad la conducta de los decuriones contraria a sus decretos. Pueden hacerlo a distancia, desde su palacio, sin necesidad siquiera de enviar emisarios a provincias. Otra cosa hubiera sido conseguir que sus oficiales castigaran a los que circunvenían sus prohibiciones. Tengo la sospecha de que el éxito de la Lex Non Dubium (y su reflejo en el art. 6.3 CC) tiene mucho que ver con este efecto simbólico de la nulidad, producido por las meras palabras, sin necesidad (ni, acaso, intención) de modificar la realidad.

${ }_{50}$ El hecho de que tanto la invalidez como la sanción tuvieran eficacia disuasoria no justificaría asimilar la invalidez a la sanción. Como es bien sabido, también determinados impuestos y tasas (sobre el alcohol y el tabaco, por ejemplo) tienen fines disuasorios, sin que puedan por ello considerarse sanciones en ningún sentido técnico. Me he ocupado de las relaciones entre invalidez y sanción (conceptos que creo deben mantenerse separados) en «¿’Sanción de invalidez"? Los conceptos de invalidez y de sanción», Ponencia en el Coloquio sobre Invalidez e ineficacia de los actos jurídicos, Zaragoza, 9 y 10 de noviembre de 2006, en línea en NUL: Estudios sobre invalidez e ineficacia, 2006 (EspecialColoquio), http://www.codigo-civil.info/nulidad/lodel/ document.php?id=249.

${ }^{51} \mathrm{La}$ nulidad tampoco «puede verse como una sanción, si es que es un rasgo distintivo de ésta el estar dirigida a desalentar comportamientos disvaliosos» (NINO, C. S., 1985: La validez del Derecho, Buenos Aires: Astrea, p. 205). 
cia de normas prohibitivas», pues éstas muy frecuentemente acompañan a las normas de incompetencia en razón del contenido de los actos o de la incompatibilidad de su contenido normativo con normas superiores. Pero no deja de ser cierto que en un ámbito que puede ser muy amplio las normas de invalidez guían la conducta de los sujetos a la manera de las normas técnicas (persuadiendo, pero no intimidando), más como recomendaciones o advertencias que como preceptos o mandatos («si no actúas como dice la ley, no alcanzarás tu propósito»). La frustración del interés del sujeto al resultar su acto inútil no es una consecuencia añadida por la ley (imputada a la conducta del sujeto), sino causada por la conducta misma ${ }^{52}$. Al Estado le es indiferente que el sujeto alcance o no su propósito y, por tanto, cuál sea su conducta al respecto.

2. Hay casos en que, por razones intrínsecas, no es pensable una finalidad disuasoria. Son obvios los supuestos de invalidez por error. La norma que señala la invalidez del contrato viciado por error no tiene ninguna posibilidad de servir de orientación para el que sufre el error «No caigas en el error porque entonces tu contrato será inválido», sería la pintoresca regla técnica, sólo atendible por quien supiera lo que no sabe. Como para nada puede orientar la conducta del testador la norma que prevé la anulación del testamento en el caso de que haya preterido no intencionalmente a alguno de sus legitimarios. En los casos de dolo o de violencia, ciertamente la norma invalidante no pretende (no podría) guiar la conducta de quien los sufre: pienso que tampoco pretende guiar la conducta de quien los utiliza, sino que esta finalidad la tiene la norma de conducta que les prohíbe utilizarlos.

Creo que no tienen la finalidad de orientar la conducta de los sujetos las normas que invalidan los contratos celebrados por menores o incapaces. Es obvio respecto de los que carecen de aptitud natural de entender y querer. Pero tampoco para quienes la tienen hay propiamente una prohibición de contratar. Desde otro punto de vista, ciertamente, la norma puede desalentar a los mayores de edad de contratar con menores o incapaces, pero no es seguro que ésta sea su finalidad.

3. En sentido contrario, hay también muchos casos en que la finalidad de la norma invalidante es desalentar la realización de los actos: en todos los casos en que la invalidez está prevista como consecuencia de la infracción de una prohibición (más aún si no se prevé ninguna otra consecuencia sancionadora).

Otra cosa es que, en efecto, la invalidez sea adecuada o suficiente para disuadir de realizar la conducta prohibida. En el terreno de la eficacia y la efectividad social de la norma, son muchas las circunstancias de la realidad (además de la configuración de la norma) que pueden excluir o minorar este efecto disuasorio. Entramos en un terreno poco o nada explorado. Propongo y comento algunos ejemplos.

a) No hay efecto disuasorio cuando a los sujetos les es indiferente la validez, es decir, la posibilidad de utilizar la coacción estatal para lograr el cumplimiento de los deberes resultantes del acto. La Ley de Defensa de la Competencia (Ley 16/1989, de 17 de julio) proporciona un buen terreno para la reflexión. El n. ${ }^{\circ} 2$ de su art. 1 dispone que «son nulos de pleno derecho los acuerdos, decisiones y recomendaciones

${ }^{52}$ Utilizo categorías y clasificaciones tomadas de BobBio, N., 1994: «Sanzione», Contributi ad un dizionario giuridico, Turín: Giappichelli, pp. 307-333; en particular, pp. 313-315 y 321-322 (1969: «Sanzione», en Novissimo Digesto Italiano, XVI, Turín: Utet, pp. 530-540). 
que estando prohibidos en virtud de lo dispuesto en el n. ${ }^{\circ} 1$, no estén amparados por las exenciones previstas en la presente Ley». Pero el legislador parece consciente de que la nulidad de poco serviría para desalentar estos actos, por lo que establece a continuación un catálogo de sanciones (en particular multas, sancionadoras y coercitivas). Sobre todo, ocurre que no sólo están prohibidos los acuerdos, decisiones o recomendaciones que tengan por objeto, produzcan o puedan producir el efecto de impedir, restringir o falsear la competencia, sino también toda «práctica concertada o conscientemente paralela» con el mismo objeto o consecuencia. Son esas "prácticas" lo que realmente se quiere erradicar y para ello la nulidad carece de sentido. Cuando haya acuerdos, el problema principal no es su existencia, pues, al menos si son claramente ilegales, nadie pretenderá exigir su cumplimiento ante los tribunales: el problema es que se están "cumpliendo", es decir, que voluntariamente las empresas están realizando las prácticas contrarias, de forma concertada o conscientemente paralela.

Consideraciones similares pueden hacerse sobre el pacto de non licitando, tendente a alterar el resultado de la subasta (ejemplo clásico de contrato contrario a la moral o las buenas costumbres): rara vez el problema será que una de las partes reclama su aplicación en juicio. La norma que tacha de inválido al pacto poco puede hacer para desincentivar las conductas concertadas.

En general, puede sugerirse que cuando las partes tienen razones suficientes, ajenas al sistema jurídico, para mantener la conducta pactada, la norma de invalidez es ineficaz para modificar esta conducta. Su efecto parece ser exclusivamente el simbólico de mantenimiento de la santidad de la norma.

b) El caso del contrato usurario suscita reflexiones distintas. La validez interesa al prestamista, pues para el prestatario es razón importante para cumplir (pagando los intereses y restituyendo el capital) la posibilidad de ser condenado a ello por un tribunal. De hecho, es frecuente que el prestatario alegue el carácter usurario del préstamo sólo al ser demandado por incumplimiento.

Ahora bien, que la nulidad alcance efectos disuasorios para el prestamista depende de las consecuencias posteriores a la declaración de nulidad. Si, siguiendo un esquema "clásico", declarada la nulidad el prestatario ha de restituir de inmediato el capital, el cálculo coste-beneficio puede mover a los prestamistas a seguir prestando con intereses usurarios, previendo una probabilidad escasa de que los prestatarios hagan valer la nulidad junto con el hecho de que, en estos casos poco probables, recuperarán de inmediato el capital (que, simplemente, habrá quedado improductivo durante el tiempo transcurrido si a su vez han de restituir todos los intereses percibidos: menor efecto disuasorio tendría todavía una regulación que le permitiera retener el interés usual o el legal ${ }^{53}$.

Una regulación que privara al usurero de la acción para recuperar el capital —al menos, durante el tiempo pactado para el préstamo - sería, sin duda, mucho más disuasoria. Claro que establecería, precisamente, una sanción: una pena de derecho privado. Algo que la doctrina y la jurisprudencia españolas ven con especial recelo, pero que podría fundarse en lo dispuesto en los arts. 1.305 y 1.306. Lo que quiero señalar aquí es que esta regulación de las consecuencias de haber realizado atribu-

53 Sobre la ley española y las diversas actitudes de sus intérpretes puede verse DELGADO, J., y PARRA, M. Á., 2005: Las nulidades de los contratos, Madrid: Dykinson, pp. 311-316. 
ciones patrimoniales con causa ilícita o torpe (no sólo en el caso mencionado de la usura), que tiene en el Código un indudable sentido punitivo con previsibles efectos disuasorios, suele ser evitada por los tribunales y combatida por los autores ${ }^{54}$. ¿Acaso porque les parece suficiente sanción la declaración de nulidad? Desde el punto de vista de la eficacia disuasoria de la sanción, es claro que la mera nulidad resulta inútil. Cabe pensar que los juristas a quienes las "penas privadas" parecen inconvenientes —aunque los "daños punitivos" no son ya totalmente ajenos al ordenamiento español y parece que su reconocimiento va creciendo-, si afirman que «la nulidad es una sanción» es porque saben que, en realidad, no es una sanción punitiva y no tiene por sí efecto disuasorio.

4. Los contratos simulados es otro campo interesante para comprobar en qué forma la invalidez desalienta la realización de los actos, si es que lo hace. No entraré aquí en explicaciones sobre la simulación y sus tipos: me basta con señalar que autores y tribunales son unánimes en que el contrato simulado es nulo de pleno derecho (y en que el contrato disimulado es válido si tiene los requisitos de fondo y forma), aunque disientan en el fundamento de esta nulidad. Pues bien, la nulidad es precisamente lo que desean las partes. La nulidad del contrato simulado no tiene la menor capacidad disuasoria, antes bien, es una condición necesaria para que los particulares los concierten. Paradójicamente, el efecto disuasorio lo tendría la validez de lo declarado y sólo aparentemente querido.

En este como en los ejemplos anteriores no estoy formulando propuestas de política legislativa, sino analizando teóricamente las potencialidades disuasorias que en diversos contextos pueden apreciarse en la invalidez, para mostrar que tampoco en este sentido funcional y sociológico de las sanciones puede decirse que la invalidez, en general, lo sea ${ }^{55}$.

${ }^{54}$ Desde el punto de vista del análisis económico del Derecho, se ha defendido que las reglas del Common Law sobre contratos ilegales son eficientes, precisamente porque niegan toda acción (cumplimiento, rescisión y restitución) a ambas partes, con excepciones casuísticas que no se alejan mucho de lo dispuesto en nuestros arts. 1.305-1.306 CC (Kostritsky, J. P., 1988: «Illegal Contracts and Efficient Deterrence: A Stady in Modern Contract Theory», Iowa Law Review, vol. 74, p. 115. Accesible en SSRN: http://ssrn.com/abstract=923577). En ambiente académico muy distinto (aunque con alguna influencia de Law and Economics) se ha recordado recientemente el punto de vista de CANARIS (1990) sobre la negación de restitución que resulta del $\$ 817$ BGB en los casos de prestación contraria a la ley o a las buenas costumbres: la regla (que incluye los contratos usurarios) estaría justificada por su eficacia de prevención general (WAGNER, G., 2006: «Prëvention und Verhaltenssteuerung durch Privatrecht-Anmassung oder legitime Ausgabe?», Archiv für die Civilistische Praxis, Bd. 206, en particular pp. 364-368).

55 En cuanto a la simulación, creo, con P. SALVADOR, que no está prohibida en nuestro Derecho (por tanto, está permitida "en sentido débil"), pero que no hay razones para propiciarla. Añado que, en ciertos casos genéricos, convendría desalentarla; para estos casos, cabría considerar dar validez al acuerdo aparente. P. SALVADOR recuerda la postura de CARBONNIER, partidario de impedir en lo posible la simulación, y da cuenta de cómo en Francia, entre otros supuestos, la simulación del precio en la compraventa de inmuebles tiene la consecuencia de que para las partes el precio simulado sea el realmente debido. Esto, sin duda, desincentiva al vendedor de hacer constar en la escritura un precio más bajo cuando se quiere cobrar aparte un sobreprecio (acaso "en negro") (SALVADOR, P., «Simulación negocial, deberes de veracidad y autonomía privada», p. 48, en Salvador, P., y Silva Sánchez, J. M., 1999: Simulación y deberes de veracidad, Madrid: Civitas. 